\title{
The influence of gender, age, education and household size on meal preparation and food shopping responsibilities
}

\author{
Lee A Flagg ${ }^{1}$, Bisakha Sen ${ }^{2}$, Meredith Kilgore ${ }^{2}$ and Julie L Locher ${ }^{3, *}$
}

'Department of Sociology, University of Alabama at Birmingham, Birmingham, AL, USA: ${ }^{2}$ Department of Health Care Organization and Policy, University of Alabama at Birmingham, Birmingham, AL, USA: ${ }^{3}$ Departments of Medicine and Health Care Organization and Policy, University of Alabama at Birmingham, $\mathrm{CH} 19218 \mathrm{~F}, 1720$ 2nd Avenue South, Birmingham, AL 35294-1 152, USA

Submitted 4 March 2013: Final revision received 29 May 2013: Accepted 24 July 2013: First published online 30 August 2013

\begin{abstract}
Objective: To examine the extent to which the gendered division of labour persists within households in the USA in regard to meal planning/preparation and food shopping activities.

Design: Secondary analysis of cross-sectional data.

Setting: 2007-2008 US National Health and Nutrition Examination Survey.

Subjects: Sub-sample of 3195 adults at least 20 years old who had a spouse or partner.

Results: Analyses revealed that the majority of women and men reported they shared in both meal planning/preparing and food shopping activities (meal planning/ preparation: women 54\% and men 56\%; food shopping: women $60 \%$ and men $57 \%$ ). Results from multinomial logistic regression analyses indicated that, compared with men, women were more likely to take primary responsibility than to share this responsibility and less likely to report having no responsibility for these tasks. Gender differences were observed for age/cohort, education and household size. Conclusions: This study may have implications for public health nutritional initiatives and the well-being of families in the USA.
\end{abstract}

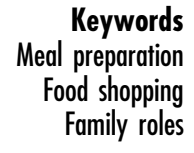

Feeding the family, a primary component of housework, has traditionally been the responsibility of women in the $\mathrm{USA}^{(1)}$. Feeding the family is an integral part of caring for family members and entails a considerable amount of labour. Both DeVault ${ }^{(1)}$ and Carrington ${ }^{(2)}$ have outlined the many and varied activities that are involved in the unpaid work of feeding the family. These include: learning individual family member's food preferences; learning about food, nutrition and preparation techniques; planning meals; food shopping, which includes learning where to buy food, deciding where to shop, scheduling shopping trips, financing food purchases, making the purchases, developing a stockpile of food and monitoring those supplies; preparing the meals; serving meals; actually feeding members of the family; and cleaning up after meals ${ }^{(1,2)}$.

In addition to physical work, caretaking and feeding the family can also involve a lot of emotion work ${ }^{(1)}$. For example, Locher and colleagues have described the additional burden and stress involved with feeding the family when one of its members has cancer ${ }^{(3)}$. Furthermore, the amount of food choices individuals must make within increasingly complex food systems with a multitude of options, all of which may have important health consequences, highlights the effort involved and the significance of meal planning and shopping ${ }^{(4,5)}$. On the other hand, feeding the family can also be an expression of love and caring and, thus, can be a positive experience for caretakers relative to other household tasks ${ }^{(6)}$.

\section{Gender}

The wide range of activities and important responsibilities involved with feeding the family has historically been delegated to the women of the household ${ }^{(1)}$. Recent evidence, however, suggests that the gendered division of labour has declined, especially over the past two decades $^{(7)}$. Beginning in the 1980s, women decreased their time spent on unpaid household work as men's contributions rose, particularly in cooking, cleaning and child care. The decreased time women spend on housework has also been attributed to compositional factors, including increased female labour force participation, delay of marriage and lower fertility ${ }^{(8,9)}$.

\section{Marital status}

The pattern of greater commitment of time and effort towards household responsibilities among women holds true regardless of marital status, but the gap in household work is greatest among married persons ${ }^{(10)}$. However, married persons who cohabit prior to marriage are more 
likely to have a more equal division of housework ${ }^{(11)}$. This pattern is likely due to these couples having less traditional ideologies that extend to gender roles. Overall, divorced and widowed men do more housework, particularly more cleaning and cooking, than married men ${ }^{(10)}$. Time spent on housework among never married, cohabiting and married men is more similar ${ }^{(10)}$, although married men may have to take on more caretaking roles, such as meal preparation, if their partner becomes ill $^{(3)}$.

\section{Age/cobort}

One would also expect that age is associated with decreased sharing of household tasks between partners. This trend is seen as a function of cohort, rather than age, as cohort succession is more important in changing gender attitudes than individual changes in attitudes ${ }^{(12)}$. Cohort effects are attributable to younger and more egalitarian cohorts ageing into adulthood and replacing earlier and more traditional cohorts ${ }^{(13)}$. Therefore, it would be expected that older women compared with younger women would be more likely to be primarily responsible for household tasks, including feeding the family. Even though gender-role attitudes tend to be stable over time for individuals, one longitudinal study found both men and women became more egalitarian in their attitudes over time. These gender-role attitude changes were influenced by experiences of continuing education, movement in and out of the workforce, marriage and parenthood ${ }^{(14)}$. Another study also found that women's employment may be behind the change in attitudes over the life course ${ }^{(7)}$.

\section{Education}

Similar to results found in the longitudinal study by Fan and Marini ${ }^{(14)}$, it has also been found that higher levels of education are associated with more egalitarian attitudes about gender ${ }^{(7,13)}$. Education provides an avenue for exposure to more egalitarian ideas and can debunk many gender stereotypes ${ }^{(13)}$. One study has shown that spouse's egalitarianism and spouse's education are positively associated with one's own egalitarianism ${ }^{(15)}$. Furthermore, those who are highly educated may tend to have higher status jobs and work more hours, leading an increase in the likelihood of sharing responsibility for household tasks ${ }^{(16,17)}$. Therefore, it would be expected that those couples with more education are more likely to share household tasks. At the same time, the association between education and attitudes towards women's work and family roles appears weaker among cohorts born after 1945 with educational convergence of attitudes in the late 1970 s to the early $1990 \mathrm{~s}^{(7,12)}$. This suggests that, among recent cohorts in particular, education may no longer be a strong predictor of the division of household tasks.

\section{Children and family size}

Working wives still continue to spend more time maintaining the home than working husbands, even in the absence of children. But when the family does have children, women spend even more time doing household chores ${ }^{(18)}$, despite the fact that the presence of a young child is associated with women's egalitarianism (while the number of children in the home is inversely related to men's egalitarianism $)^{(15)}$. Nevertheless, one study found that children are negatively associated with gender egalitarianism for both men and women ${ }^{(19)}$. Even when couples begin their lives together both working in the public sphere, the advent of children tends to contribute to an imbalance in the symmetry of household work that the couple had previously established ${ }^{(20)}$. In general, working women use their earnings to outsource domestic tasks and reduce their burden ${ }^{(21)}$. The competing demands of employed parents' time may be leading to fewer meals eaten at home and lower nutritional value of meals ${ }^{(22)}$. Furthermore, children of larger families tend to be at the greatest nutritional risk ${ }^{(23)}$.

\section{Research questions and bypotbeses}

Overall, it is expected that trends in women's decreased and men's increased housework hours will continue and there may be more sharing of the household tasks between men and women ${ }^{(24)}$. Yet despite historical shifts in who does what regarding household work, it has been estimated that women continue to do at least twice as much work in the home as men ${ }^{(24-27)}$. Furthermore, there appears to be a division within housework along feminine and masculine lines with women doing more of the feminine housework and men doing more of the masculine housework ${ }^{(28)}$. This is the focus of our work. Specifically, we hypothesize that:

1. Women are more likely to assume primary responsibility for meal planning/preparing and food shopping in the home, whereas men are more likely to assume no responsibility for these tasks.

2. Age will increase women's likelihood of assuming primary responsibility for meal planning/preparing and food shopping and increase men's likelihood of assuming no responsibility.

3. Education will decrease women's likelihood of assuming primary responsibility for meal planning/preparing and food shopping in the home, as well as decrease men's likelihood of assuming no responsibility.

4. The number of children in the household will increase women's likelihood of reporting primary responsibility for meal planning/preparing and food shopping and also increase men's likelihood of reporting no responsibility for these tasks.

\section{Methods}

\section{Study design and data collection}

Beginning in the 1960s, the Division of Health and Nutrition Examination Surveys of the National Center for 
Health Statistics, which is a part of the Centers for Disease Control and Prevention, has conducted a series of health and nutrition examination surveys. The National Health and Nutrition Examination Survey (NHANES) began in 1971 and were collected periodically until 1994. Beginning in 1999, NHANES became a biennial survey. Each year, approximately 5000 persons are interviewed in their homes and undergo a health examination ${ }^{(29)}$.

NHANES uses a stratified, multistage probability sample of its target population of civilian non-institutionalized persons in the USA. In total, the 2007-2008 NHANES cycle collected data from 10149 individuals of all ages between January 2007 and December 2008 ${ }^{(29)}$.

\section{Sample selection}

Because the focus of our study was on determining who was primarily responsible for meal planning/preparing and food shopping, we restricted our sample to adults aged 20 years and over. Additionally, we restricted our sample to those respondents who reported having a spouse or living with a partner, and there were two or more adult persons in the household (thus excluding those who reported having a spouse/partner but did not currently reside with them). This created a sample of 3517 adults. Due to missing data on the dependent variables and key covariates, the final analytic sample consisted of 3195 adults (91\%).

\section{Measurements}

In 2007, NHANES added a Flexible Consumer Behavior Survey (FCBS) module to the Diet Behavior and Nutrition Questionnaire. This module has two components: (i) a core set of questions asked in the in-home interview and (ii) a set of supplementary questions asked in the follow-up telephone interview. The FCBS core set of questions collects information on individuals' food choices, including meal planning/preparing and food shopping status in the home ${ }^{(30)}$.

\section{Dependent variables}

Our dependent variables of interest were the respondents' status at home regarding meal planning/preparing duties and food shopping duties.

\section{Meal planning and preparing status in the bome}

This variable was measured by asking respondents, 'Are you the person who does most of the planning or preparing of meals in your family?' Those who answered 'yes', 'sometimes' or '50/50' were all coded as 'yes' by NHANES. Respondents were also asked, 'Do you share in the planning or preparing of meals with someone else?' with 'yes' and 'no' as response options. We combined responses from these questions to create our categories of 'duty'. Specifically, those who reported that they did most of the planning/preparing and did not share this responsibility with another person were coded as having 'main meal planning/preparing duty'. Those who reported that they did most of the planning/preparing and that they shared this responsibility (i.e. responded 'yes' to the second question) were coded as 'shared meal planning/preparing duty'. Lastly, those who responded 'no' to both questions were coded as 'no meal planning/ preparing duty'.

\section{Food shopping status in the bome}

Survey participants were also asked questions about food shopping. The first question asked, 'Are you the person who does most of the shopping for food in your family?' Those who answered 'yes', 'sometimes' or '50/50' were coded as 'yes' by NHANES. The second question was 'Do you share in the shopping for food with someone else?' with response options consisting of 'yes' and 'no'. The same coding scheme for meal planning/preparing status was used for food shopping, and individuals were coded into three categories: 'main food shopping duty', 'shared food shopping duty' and 'no food shopping duty'.

\section{Covariates}

We included demographic factors, socio-economic factors, and household and family structure factors in our analyses.

\section{Demographic factors}

Gender was measured nominally with men being the reference category. Respondent's age at screening was reported in years. Race was coded into four categories: White, Black, Hispanic and other.

\section{Socio-economic factors}

Education was coded into two categories: high school or less (diploma, GED (General Education Development) or equivalent, or less) $v$. some college or more (some college, associate's degree, or above). To measure economic status, consistent with other studies using NHANES data $^{(31)}$, we used the income-to-poverty ratio, which is defined as the ratio of the family income to the appropriate poverty threshold. To define poverty status, income criteria used by the US Census Bureau take into account family size and composition. This variable is then calculated as the ratio of the family's total income before taxes (excluding capital gains and non-cash benefits) to their corresponding poverty threshold ${ }^{(32)}$.

\section{Housebold and family structure}

Marital status was broken down into two categories: living with partner and married. Those who were married composed the reference category. Number of children is not available in NHANES data, but household size was used as a proxy for this variable. In most cases, in households with greater than two persons, the additional members are likely to be dependant children. We acknowledge that there may be some cases where subsequent members may be other adult relatives, or other 
adults residing temporarily with the household. Household size ranged from two to seven. Those with seven or more members in the household were top-coded as seven in the NHANES data.

\section{Analytic strategy}

Prior to running any regression analyses, descriptive statistics as well as $\chi^{2}$ tests were run to test for differences in prevalences of the two dependent variables between genders. To test the study's hypotheses, separate regression analyses were run for the two dependent variables. For each dependent variable, multinomial logistic regression was run on the entire sample and then on men and women separately. Multinomial logistic regression is a widely used method that is an extension of the standard binary logistic model, and is designed to handle cases where the dependent variable can belong to more than two categories rather than a dichotomous variable as in the case of the standard binary logistic model ${ }^{(33)}$. They are sometimes also referred to as 'polychotomous' or 'polytomous' logistic regression models. One of the categories is chosen to be the 'reference category' or 'base category', and the regression model then simultaneously estimates the odds of belonging to each of the other categories relative to the reference category. For this analysis, shared meal planning/preparing and shared food shopping were used as the reference categories. The other categories consisted of main meal planning/preparing or food shopping and no meal planning/preparing or food shopping. Therefore, in our full sample analyses, the $i$ th respondent's odds of belonging to any other category $j$ relative to sharing meal planning/preparing or food shopping responsibility is:

$$
P_{i j} / P_{i 1}=\exp \left(F E M A L E_{i} \beta_{j}+X_{i} \alpha_{j}\right), \quad(j=2,3) .
$$

And the log-odds of belonging to any other category $j$ relative to that of shared responsibility for meal planning/ preparing or food shopping is derived as:

$$
\mu_{i j}=\log P_{i j} / P_{i 1}=F E M A L E_{i} \beta_{j}+X_{i} \alpha_{j}
$$

where FEMALE is a binary variable with male as the reference category. $X_{i}$ refers to the vector of additional control variables that were previously described. We then estimated multinomial logistic models separately for men and women. This helps inform on gender differences in how $X_{i}$ is associated with the odds of belonging to any other category $j$ relative to sharing meal planning/preparing or food shopping responsibility. The models were estimated using the statistical software package Stata SE Version 10 for Windows

\section{Results}

Descriptive statistics for the sample are presented in Table 1 for both men and women. Fifty-four per cent of the sample consisted of men (1914/3517) and $46 \%$ of the sample consisted of women (1603/3517). Only 6\% and $7 \%$ of men reported main responsibility for meal planning/preparing and food shopping, respectively. In contrast, $40 \%$ and $36 \%$ of women reported main responsibility for these duties. Similar patterns, but in the

Table 1 Descriptive statistics of the study sample, men ( $n$ 1914) and women ( $n$ 1603) separately; 2007-2008 US National Health and

\begin{tabular}{|c|c|c|c|c|c|c|}
\hline \multirow[b]{2}{*}{ Variable } & \multicolumn{3}{|c|}{ Men } & \multicolumn{3}{|c|}{ Women } \\
\hline & Mean & SD & Range & Mean & SD & Range \\
\hline \multicolumn{7}{|l|}{ Meal planning/preparing } \\
\hline Main meal planner/preparer & 0.06 & - & $0-1$ & $0 \cdot 40$ & - & $0-1$ \\
\hline Shared meal planning/preparing & 0.54 & - & $0-1$ & 0.56 & - & $0-1$ \\
\hline No meal planning/preparing & 0.40 & - & $0-1$ & 0.04 & - & $0-1$ \\
\hline \multicolumn{7}{|l|}{ Food shopping } \\
\hline Main food shopper & 0.07 & - & $0-1$ & 0.36 & - & $0-1$ \\
\hline Shared food shopping & $0 \cdot 60$ & - & $0-1$ & 0.57 & - & $0-1$ \\
\hline No food shopping & 0.33 & - & $0-1$ & 0.06 & - & $0-1$ \\
\hline Age (years) & $52 \cdot 57$ & $16 \cdot 63$ & $20-80$ & $49 \cdot 12$ & $16 \cdot 04$ & $20-80$ \\
\hline \multicolumn{7}{|l|}{ Race/ethnicity } \\
\hline White & 0.49 & - & $0-1$ & 0.49 & - & $0-1$ \\
\hline Black & $0 \cdot 17$ & - & $0-1$ & $0 \cdot 14$ & - & $0-1$ \\
\hline Hispanic & 0.29 & - & $0-1$ & $0 \cdot 33$ & - & $0-1$ \\
\hline Other & 0.05 & - & $0-1$ & 0.04 & - & $0-1$ \\
\hline \multicolumn{7}{|l|}{ Marital status } \\
\hline Married & $0 \cdot 88$ & - & $0-1$ & $0 \cdot 89$ & - & $0-1$ \\
\hline Living with partner & $0 \cdot 12$ & - & $0-1$ & $0 \cdot 11$ & - & $0-1$ \\
\hline Household size & $3 \cdot 36$ & 1.52 & $2-7$ & $3 \cdot 43$ & 1.53 & $2-7$ \\
\hline \multicolumn{7}{|l|}{ Education } \\
\hline High school or less & 0.56 & - & $0-1$ & 0.53 & - & $0-1$ \\
\hline Some college or more & $0 \cdot 44$ & - & $0-1$ & 0.47 & - & $0-1$ \\
\hline Family income-to-poverty ratio & $2 \cdot 76$ & $1 \cdot 62$ & $0-5$ & $2 \cdot 79$ & $1 \cdot 61$ & $0-5$ \\
\hline
\end{tabular}
Nutrition Examination Survey 
Table 2 Multinomial logistic regression model results for meal planning/preparing for the entire sample; 2007-2008 US National Health and Nutrition Examination Survey

\begin{tabular}{|c|c|c|c|c|c|c|}
\hline \multirow[b]{2}{*}{ Predictor } & \multicolumn{3}{|c|}{$\begin{array}{c}\text { Category } 1 \\
\text { (main meal planner/preparer) }\end{array}$} & \multicolumn{3}{|c|}{$\begin{array}{c}\text { Category } 2 \\
\text { (no meal planning/preparing) }\end{array}$} \\
\hline & $B$ & SE & OR & $B$ & SE & OR \\
\hline Femalet & $1 \cdot 93^{\star \star \star}$ & $0 \cdot 12$ & $6 \cdot 92$ & $-2 \cdot 37^{\star \star \star}$ & $0 \cdot 15$ & 0.09 \\
\hline Age & 0.00 & 0.00 & $1 \cdot 00$ & $0.02^{* * *}$ & 0.00 & $1 \cdot 02$ \\
\hline \multicolumn{7}{|l|}{ Race/ethnicity } \\
\hline Black & $0 \cdot 15$ & $0 \cdot 14$ & $1 \cdot 16$ & -0.25 & $0 \cdot 14$ & 0.78 \\
\hline Hispanicł & $0 \cdot 14$ & $0 \cdot 12$ & $1 \cdot 15$ & $0.24^{*}$ & $0 \cdot 12$ & $1 \cdot 28$ \\
\hline Other $\ddagger$ & 0.20 & $0 \cdot 24$ & $1 \cdot 22$ & -0.36 & 0.25 & $0 \cdot 70$ \\
\hline \multicolumn{7}{|l|}{ Marital status } \\
\hline Living with partner§̧ & $-0 \cdot 40^{*}$ & $0 \cdot 17$ & 0.67 & $-0 \cdot 38^{*}$ & $0 \cdot 17$ & 0.69 \\
\hline Household size & -0.04 & 0.04 & 0.96 & $0 \cdot 13^{\star \star}$ & 0.04 & $1 \cdot 14$ \\
\hline \multicolumn{7}{|l|}{ Education } \\
\hline Some college or morell & $-0 \cdot 16$ & $0 \cdot 11$ & 0.85 & $-0 \cdot 17$ & $0 \cdot 11$ & $0 \cdot 84$ \\
\hline Family income-to-poverty ratio & -0.02 & 0.03 & 0.98 & -0.07 & 0.04 & 0.93 \\
\hline Constant & $-1 \cdot 97$ & & & $-1 \cdot 38$ & & \\
\hline Likelihood ratio $\chi^{2}$ & & & & & & $1092 \cdot 83^{\star \star \star}$ \\
\hline Pseudo $R^{2}$ & & & & & & 0.17 \\
\hline
\end{tabular}

opposite direction, were seen for men and women who reported no responsibility for these tasks. A majority of men and women (between 54\% and 60\%) reported sharing the meal planning/preparing and food shopping.

The rest of the descriptive statistics for the sample were very similar between men and women. Overall, the sample had a mean age of approximately 50 years, a mean household size of about $3 \cdot 4$ people, and a mean family income-to-poverty ratio of about $2 \cdot 8$. The sample was predominantly white, married and had a high school education or less, although a large percentage had at least some college education ( $44 \%$ of men, $47 \%$ of women). There was a strong relationship between meal planning/ preparing status and food shopping status $\left(\chi^{2}=2800\right.$, $P<0 \cdot 001$ ), with $68 \%$ of those who reported main meal planning/preparing status also reporting main food shopping status and $84 \%$ of those who reported shared meal planning/preparing status also reporting shared food shopping status.

Results from the first multinomial logistic regression analysis, which uses the pooled sample of men and women, are presented in Table 2 . Women had a higher likelihood than men of reporting main responsibility and a lower likelihood of reporting no responsibility compared with the reference category shared meal planning/ preparing. Older individuals were more likely to report no responsibility than shared responsibility. In addition, compared with Whites, Hispanics were more likely to report no meal planning/preparing duty than shared duty. Those who cohabited appeared to be more likely than those who were married to share responsibility for meal planning/preparation. Lastly, those in larger households were more likely to report having no responsibility for meal planning/preparing than shared responsibility.

Table 3 shows the results from separate regression analyses for women and men. For women, none of the predictor variables in the model showed a significant relationship with the likelihood of having the main responsibility or no responsibility compared with shared responsibility. But for men, age was highly statistically significant, indicating that older men were more likely to report having no responsibility for meal planning/ preparing than to share this responsibility. Compared with White men, Black men were more likely to report main meal planning/preparing duty than shared, as well as less likely to report no meal planning/preparing duty than shared. Men of other races were more likely to report main responsibility for these tasks than shared responsibility. In addition, men who cohabited were less likely to report no responsibility compared with sharing responsibility. Men in larger sized households were less likely to report being the main meal planner/preparer than to share this responsibility and were more likely to report that they have no responsibility than share these tasks. Education was not significant at the 0.05 level for women or men.

Results from the regression analysis for the second dependent variable, food shopping, are reported for the full sample in Table 4 and by gender in Table 5. Consistent with the previous analysis, women were more likely to report main food shopping duty and less likely to report no food shopping duty, compared with men. Older individuals were more likely to report no food 
Table 3 Multinomial logistic regression model results for meal planning/preparing for females and males separately; 2007-2008 US National Health and Nutrition Examination Survey

\begin{tabular}{|c|c|c|c|c|c|c|}
\hline \multirow[b]{2}{*}{ Predictor } & \multicolumn{3}{|c|}{$\begin{array}{c}\text { Category } 1 \\
\text { (main meal planner/preparer) }\end{array}$} & \multicolumn{3}{|c|}{$\begin{array}{c}\text { Category } 2 \\
\text { (no meal planning/preparing) }\end{array}$} \\
\hline & $B$ & SE & OR & $B$ & SE & OR \\
\hline \multicolumn{7}{|l|}{ Women } \\
\hline Age & 0.00 & 0.00 & 1.00 & 0.01 & 0.01 & $1 \cdot 01$ \\
\hline \multicolumn{7}{|l|}{ Race/ethnicity } \\
\hline Blackt & 0.04 & $0 \cdot 16$ & 1.04 & 0.54 & $0 \cdot 38$ & $1 \cdot 72$ \\
\hline Hispanict & $0 \cdot 10$ & $0 \cdot 13$ & $1 \cdot 11$ & $0 \cdot 41$ & $0 \cdot 34$ & $1 \cdot 50$ \\
\hline Othert & 0.02 & $0 \cdot 28$ & $1 \cdot 02$ & 0.52 & $0 \cdot 64$ & $1 \cdot 69$ \\
\hline \multicolumn{7}{|l|}{ Marital status } \\
\hline Living with partnerł & -0.36 & $0 \cdot 19$ & $0 \cdot 70$ & -0.22 & 0.51 & $0 \cdot 80$ \\
\hline Household size & 0.02 & 0.04 & $1 \cdot 02$ & -0.03 & $0 \cdot 12$ & 0.96 \\
\hline \multicolumn{7}{|l|}{ Education } \\
\hline Some college or more $\S$ & $-0 \cdot 14$ & $0 \cdot 12$ & $0 \cdot 87$ & $0 \cdot 20$ & $0 \cdot 31$ & $1 \cdot 22$ \\
\hline Family income-to-poverty ratio & -0.02 & 0.04 & 0.98 & -0.01 & $0 \cdot 10$ & 0.99 \\
\hline Constant & $-0 \cdot 21$ & & & $-3 \cdot 50$ & & \\
\hline Likelihood ratio $\chi^{2}$ & & & & & & $13 \cdot 51$ \\
\hline Pseudo $R^{2}$ & & & & & & 0.00 \\
\hline \multicolumn{7}{|l|}{ Men } \\
\hline Age & 0.00 & 0.01 & 0.99 & $0.02^{\star \star \star}$ & 0.00 & $1 \cdot 02$ \\
\hline \multicolumn{7}{|l|}{ Race/ethnicity } \\
\hline Blackt & $0 \cdot 61^{*}$ & $0 \cdot 27$ & $1 \cdot 84$ & $-0 \cdot 31^{*}$ & $0 \cdot 15$ & $0 \cdot 73$ \\
\hline Hispanict & $0 \cdot 26$ & $0 \cdot 30$ & $1 \cdot 30$ & 0.24 & $0 \cdot 13$ & $1 \cdot 26$ \\
\hline Othert & $0.94^{*}$ & 0.42 & $2 \cdot 55$ & -0.42 & 0.27 & 0.66 \\
\hline \multicolumn{7}{|l|}{ Marital status } \\
\hline Living with partnerł & -0.62 & $0 \cdot 39$ & 0.54 & $-0 \cdot 40^{\star}$ & $0 \cdot 18$ & 0.67 \\
\hline Household size & $-0 \cdot 41^{* * *}$ & $0 \cdot 11$ & 0.66 & $0 \cdot 13^{* *}$ & 0.04 & $1 \cdot 14$ \\
\hline \multicolumn{7}{|l|}{ Education } \\
\hline Some college or more§ & -0.25 & $0 \cdot 25$ & $0 \cdot 78$ & -0.23 & $0 \cdot 12$ & $0 \cdot 79$ \\
\hline Family income-to-poverty ratio & 0.02 & 0.08 & $1 \cdot 02$ & -0.07 & 0.04 & 0.93 \\
\hline Constant & -0.90 & & & $-1 \cdot 40$ & & \\
\hline Likelihood ratio $\chi^{2}$ & & & & & & $118 \cdot 94^{\star \star \star}$ \\
\hline Pseudo $R^{2}$ & & & & & & 0.04 \\
\hline
\end{tabular}

$n 1452$ and 1744 , respectively. Base category is shared meal planning/preparing.

${ }^{*} P<0.05,{ }^{* \star} P<0.01,{ }^{* * \star} P<0.001$.

tCompared with White.

‡Compared with married.

§Compared with high school or less.

Table 4 Multinomial logistic regression model results for food shopping for the entire sample; 2007-2008 US National Health and Nutrition Examination Survey

\begin{tabular}{|c|c|c|c|c|c|c|}
\hline \multirow[b]{2}{*}{ Predictor } & \multicolumn{3}{|c|}{$\begin{array}{c}\text { Category } 1 \\
\text { (main food shopper) }\end{array}$} & \multicolumn{3}{|c|}{$\begin{array}{c}\text { Category } 2 \\
\text { (no food shopping) }\end{array}$} \\
\hline & $B$ & SE & OR & $B$ & SE & OR \\
\hline Femalet & $1 \cdot 67^{\star \star \star}$ & $0 \cdot 11$ & $5 \cdot 32$ & $-1 \cdot 64^{\star \star \star}$ & $0 \cdot 13$ & $0 \cdot 19$ \\
\hline Age & 0.00 & 0.00 & $1 \cdot 00$ & $0 \cdot 01^{\star \star}$ & 0.00 & $1 \cdot 01$ \\
\hline \multicolumn{7}{|l|}{ Race/ethnicity } \\
\hline Black‡ & 0.03 & $0 \cdot 14$ & $1 \cdot 03$ & $-0 \cdot 12$ & $0 \cdot 14$ & $0 \cdot 89$ \\
\hline Hispanicł & -0.07 & $0 \cdot 12$ & 0.93 & -0.05 & $0 \cdot 12$ & 0.95 \\
\hline Other‡ & $-0 \cdot 10$ & $0 \cdot 24$ & 0.90 & $-0 \cdot 66^{*}$ & $0 \cdot 27$ & 0.52 \\
\hline \multicolumn{7}{|l|}{ Marital status } \\
\hline Living with partner§ & $-0 \cdot 38^{*}$ & $0 \cdot 17$ & 0.68 & $-0 \cdot 31$ & $0 \cdot 17$ & 0.73 \\
\hline Household size & -0.04 & 0.04 & 0.96 & $0 \cdot 10^{\star *}$ & 0.04 & $1 \cdot 10$ \\
\hline \multicolumn{7}{|l|}{ Education } \\
\hline Some college or morell & -0.06 & $0 \cdot 11$ & 0.94 & $-0 \cdot 32^{\star \star}$ & $0 \cdot 11$ & $0 \cdot 73$ \\
\hline Family income-to-poverty ratio & $\begin{array}{l}-0.04 \\
-1.60\end{array}$ & 0.03 & 0.96 & $\begin{array}{l}-0.06 \\
-1.19\end{array}$ & 0.04 & 0.94 \\
\hline Likelihood ratio $\chi^{2}$ & & & & & & $721 \cdot 36^{\star \star \star}$ \\
\hline Pseudo $R^{2}$ & & & & & & 0.12 \\
\hline
\end{tabular}

$n$ 3195. Base category is shared food shopping.

${ }^{\star} P<0.05,{ }^{\star \star} P<0.01,{ }^{\star \star \star} P<0.001$.

tCompared with male.

¥Compared with White.

§Compared with married.

IICompared with high school or less. 
Table 5 Multinomial logistic regression for food shopping for females and males separately; 2007-2008 US National Health and Nutrition Examination Survey

\begin{tabular}{|c|c|c|c|c|c|c|}
\hline \multirow[b]{2}{*}{ Predictor } & \multicolumn{3}{|c|}{$\begin{array}{c}\text { Category } 1 \\
\text { (main food shopper) }\end{array}$} & \multicolumn{3}{|c|}{$\begin{array}{c}\text { Category } 2 \\
\text { (no food shopping) }\end{array}$} \\
\hline & $B$ & SE & OR & $B$ & SE & OR \\
\hline \multicolumn{7}{|l|}{ Women } \\
\hline Age & -0.01 & 0.00 & 0.99 & $0.02^{\star *}$ & 0.01 & $1 \cdot 02$ \\
\hline \multicolumn{7}{|l|}{ Race/ethnicity } \\
\hline Blackt & $-0 \cdot 13$ & $0 \cdot 17$ & $0 \cdot 88$ & $0 \cdot 10$ & 0.31 & $1 \cdot 22$ \\
\hline Hispanict & $-0 \cdot 15$ & $0 \cdot 14$ & 0.86 & $-0 \cdot 28$ & $0 \cdot 30$ & $0 \cdot 75$ \\
\hline Othert & $-0 \cdot 22$ & 0.29 & $0 \cdot 80$ & $-0 \cdot 22$ & 0.63 & $0 \cdot 80$ \\
\hline \multicolumn{7}{|l|}{ Marital status } \\
\hline Living with partnerł & $-0.54^{\star \star}$ & 0.20 & 0.58 & $-0 \cdot 16$ & $0 \cdot 44$ & 0.85 \\
\hline Household size & 0.00 & 0.04 & $1 \cdot 00$ & 0.08 & 0.09 & 1.09 \\
\hline \multicolumn{7}{|l|}{ Education } \\
\hline Some college or more $\S$ & -0.08 & $0 \cdot 12$ & 0.92 & 0.07 & 0.25 & $1 \cdot 08$ \\
\hline Family income-to-poverty ratio & $-0 \cdot 04$ & 0.04 & 0.96 & -0.04 & 0.08 & 0.96 \\
\hline Constant & $0 \cdot 15$ & & & $-3 \cdot 70$ & & \\
\hline Likelihood ratio $\chi^{2}$ & & & & & & $25 \cdot 77$ \\
\hline Pseudo $R^{2}$ & & & & & & 0.01 \\
\hline \multicolumn{7}{|l|}{ Men } \\
\hline Age & 0.00 & 0.01 & $1 \cdot 00$ & $0.01^{\star *}$ & 0.00 & $1 \cdot 01$ \\
\hline \multicolumn{7}{|l|}{ Race/ethnicity } \\
\hline Blackt & 0.46 & 0.24 & 1.59 & $-0 \cdot 15$ & $0 \cdot 15$ & $0 \cdot 86$ \\
\hline Hispanict & $0 \cdot 12$ & $0 \cdot 26$ & $1 \cdot 12$ & 0.01 & $0 \cdot 13$ & $1 \cdot 01$ \\
\hline Othert & 0.30 & 0.43 & 1.36 & $-0.71^{*}$ & 0.30 & 0.49 \\
\hline \multicolumn{7}{|l|}{ Marital status } \\
\hline Living with partnerł & 0.07 & $0 \cdot 31$ & $1 \cdot 08$ & -0.29 & $0 \cdot 18$ & $0 \cdot 74$ \\
\hline \multirow{2}{*}{\multicolumn{7}{|c|}{ Education }} \\
\hline & & & & & & \\
\hline Some college or more & 0.02 & 0.22 & $1 \cdot 02$ & $-0 \cdot 38^{\star *}$ & $0 \cdot 12$ & $0 \cdot 68$ \\
\hline Family income-to-poverty ratio & -0.03 & 0.07 & 0.97 & -0.06 & 0.04 & 0.94 \\
\hline Constant & $-1 \cdot 85$ & & & $-1 \cdot 11$ & & \\
\hline Likelihood ratio $\chi^{2}$ & & & & & & $67 \cdot 72^{\star \star \star}$ \\
\hline Pseudo $R^{2}$ & & & & & & 0.02 \\
\hline
\end{tabular}

$n 1452$ and 1743 , respectively. Base category is shared food shopping.

${ }^{\star} P<0.05,{ }^{\star \star} P<0.01,{ }^{\star \star \star} P<0.001$.

tCompared with White.

¥Compared with married.

§Compared with high school or less.

shopping duty than shared food shopping duty. Other races were less likely to report no food shopping than shared food shopping. It appeared that those who cohabited were less likely to have the main responsibility as compared with shared responsibility. Individuals in larger households were more likely to report having no food shopping responsibility than shared food shopping responsibility. Those with some college education were less likely to take no responsibility as compared with shared responsibility.

In Table 5, the results indicate that older women were more likely to report no food shopping duty. Women who cohabited were less likely to claim they are the main food shopper over shared food shopping. In addition, the results in Table 5 indicate that older men were more likely to report no food shopping than shared food shopping. Compared with White men, men of other races were less likely to report that they do no food shopping than share food shopping. In larger sized households, men were less likely to report being the main food shopper and more likely to report doing no food shopping as compared with sharing this responsibility. Men with at least some college education were less likely to report no food shopping duty in comparison to sharing food shopping duty.

\section{Discussion}

Regardless of gender, the majority of participants reported that they shared responsibility for both meal planning/ preparing and food shopping (Table 1). Compared with men, however, women were more likely to report main responsibility for both meal planning/preparing and food shopping than shared responsibility. Conversely, compared with men, women were also less likely to report no responsibility for these tasks. Thus, the first hypothesis was supported.

In addition, these relationships varied according to different characteristics. For instance, our findings revealed that older men were more likely to report no responsibility for meal planning/preparing than shared responsibility, which partially supports the second hypothesis. But older women were also more likely to report that they have no food shopping responsibilities, which is in the opposite 
direction to that hypothesized. Because both older men and women were more likely to report no responsibility for food shopping, we speculate that this result may be driven by the older adults in our sample, for whom some other household or family member is doing the food shopping $^{(34)}$. These results may also be related to the increase in adult children moving back home or the increasing time before adult children leave home in recent decades ${ }^{(35)}$.

Education was not statistically significant for either women or men in the meal planning/preparing analysis (Table 3). But for food shopping, men with at least some college education were less likely to report no responsibility and more likely to share this responsibility, providing some support for the third hypothesis. These mixed results may be due to the fact that education has become less important in influencing gender-role attitudes in recent cohorts.

Although household size did not appear to matter for women, for men, those in larger households (which may serve as a proxy for more children in the household) were more likely to report no responsibility for meal planning/preparing and food shopping. They were also less likely to report main responsibility for these tasks than shared responsibility. This provides some support for the fourth hypothesis, even though we cannot directly measure the number of children. It is interesting that almost none of the covariates of interest were significant for the women-only sample, but many of them were for men.

The major strengths of the present study include: (i) the nationally representative sample and the sample size; (ii) the most recent report of such data in more than a decade; and (iii) the reporting of who assumes primary $v$. shared $v$. no responsibility for meal planning/preparing and food shopping in contrast to the absolute amount of time spent on such activities.

Nevertheless, there are also some limitations to the study. NHANES data are cross-sectional and these types of data have inherent limitations, namely the inability to infer causation. Additionally, NHANES data do not include the actual amount of time respondents spend on such activities. To the best of our knowledge, we are unaware of any longitudinal data sets that can make these kinds of comparisons. There are other repeated crosssectional data sets that measure time use, such as the American Time Use Survey, but its data are based on a single $24 \mathrm{~h}$ recall, which may or may not reflect typical time use. In addition, this kind of data would only be able to make comparisons between men and women on a population level and not at a family or interpersonal level. In other words, respondents to the American Time Use Survey do not report their time spent in these tasks relative to their partner or other family members, while NHANES respondents do report their relative meal planning/preparing and food shopping status within the family.
It is also unknown whether men and women respond similarly to these items in the FCBS module. However, our findings reveal that men and women do give complementary responses. Both groups reported similar rates of sharing responsibility for these tasks and furthermore, $40 \%$ of women reported main responsibility for meal planning/preparing, while $40 \%$ of men reported no responsibility for meal planning/preparing (with similar results for food shopping). These results suggest that there is congruency between these two groups in reporting of these responsibilities, lending some support to the validity of the items. However, there are other limitations of the current study. Gender, marital status, age/cohort, education and household size are regarded as important in the division of household labour and caretaking responsibilities, but there are other key factors that should also be taken into consideration that were not included in the analyses. These factors include, albeit are not limited to, number and age of children in the home, workforce participation or employment status, work hours, income from employment, education level of the partner, gender of the respondent's significant other, etc., which were not available in data set, although family size was used as a proxy for number of children in the home.

Indeed, the gendered division of labour in the home can be a function of both 'doing gender' and the economic dependency of women ${ }^{(36)}$. The division of household labour has much to do with time availability, employment, work hours, occupational prestige, individual income and relative resources $(8,15,19,24,25,37-39)$. Generally, in less egalitarian couples, food chore responsibilities are assigned based on accommodating the primary breadwinner's role ${ }^{(40)}$. And although women generally take responsibility for these food-related tasks, some work has argued that when women have an income, they tend to use it towards family expenditures ${ }^{(41)}$, while other work has argued that men ultimately control the finances and food decisions due to their greater economic resources ${ }^{(42)}$. Even though variables such as employment status, occupation, hours worked and earned income were not available for this wave of the NHANES data and hence not included in the present analysis, we might speculate that our findings regarding increased food-related work for women in larger households may in part be explained because women with younger children in the household may not be working outside the home. Nevertheless, this limitation does not discount the findings concerning the main effects of gender on meal planning/preparing and food shopping, even though variables related to employment and income may be seen as possible mediators or moderators.

Although women have a considerably higher likelihood of reporting main meal planning and preparing and food shopping duty, it is interesting to note that the majority of respondents of both genders report sharing responsibility for these tasks. Future research could also employ NHANES data from the FCBS module, which 
ascertains data on meals eaten away from home, readyto-eat foods and frozen foods, to explore these phenomena further. Do convenience foods complement or substitute for sharing these food-related responsibilities in the home? Does outsourcing meals lower women's workload or spare men from these tasks? Consistent with the household production model from economics, working women may use some of their income to eat away from home given that their time is assumed to be more valuable and no longer worth the investment in household chores ${ }^{(43)}$. Lastly, what would be the public health consequences of sharing or not sharing these tasks and food outsourcing? This type of study may have important implications for nutritionally related public health initiatives and the well-being of the US population.

\section{Acknowledgements}

Sources of funding: L.A.F. is supported by the University of Alabama at Birmingham Predoctoral Training Program in Obesity-Related Research (T32 HL105349). J.L.L. is supported by the University of Alabama at Birmingham Nutrition Obesity Research Center (P30 DK056336), the National Institute on Aging (K07 AG043588) and the National Cancer Institute (R25 CA076023). The National Institutes of Health had no role in the design, analysis or writing of this article. The contents of this report are solely the responsibility of the authors and do not necessarily represent the views of the National Institutes of Health or any other organization with which the authors are affiliated. Conflict of interests: The authors have no conflicts of interest. Ethics: Informed consent was not required for this study. Institutional review board approval was obtained from the University of Alabama at Birmingham Institutional Review Board for Human Use. Authors' contributions: All authors contributed substantially to the work presented in this manuscript. L.A.F. conducted the analyses and wrote the main paper. J.L.L. jointly conceived the study with L.A.F., as well as supervised the analyses and edited the manuscript. B.S. also assisted with the conduct of the statistical analyses and edited the paper. M.K. contributed statistical advice and read the paper for critical content.

\section{References}

1. DeVault ML (1994) Feeding the Family: The Social Organization of Caring as Gendered Work. Chicago, IL: University of Chicago Press.

2. Carrington C (2000) No Place Like Home: Relationships and Family Life among Lesbians and Gay Men. Chicago, IL: University of Chicago Press.

3. Locher JL, Robinson CO, Bailey FA et al. (2010) Disruptions in the organization of meal preparation and consumption among older cancer patients and their family caregivers. Psychooncology 19, 967-974.

4. Bove CF, Sobal J \& Rauschenbach BS (2003) Food choices among newly married couples: convergence, conflict, individualism, and projects. Appetite 40, 25-41.
5. Wansink B (2007) Mindless Eating: Why We Eat More Than We Think. New York: Bantam.

6. DeVault ML (1999) Comfort and struggle: emotion work in family life. Ann Am Acad Polit Soc Sci 561, 52-63.

7. Cunningham M (2008) Changing attitudes toward the male breadwinner, female homemaker family model: influences of women's employment and education over the lifecourse. Soc Forces 87, 299-323.

8. Bianchi SM, Milkie MA, Sayer LC et al. (2000) Is anyone doing the housework? Trends in the gender division of household labor. Soc Forces 79, 191-228.

9. Waite LJ, Goldscheider FK \& Witsberger C (1986) Nonfamily living and the erosion of traditional family orientations among young adults. Am Sociol Rev 51, 541-554.

10. South SJ \& Spitze G (1994) Housework in marital and nonmarital households. Am Sociol Rev 59, 327-347.

11. Batalova JA \& Cohen PN (2004) Premarital cohabitation and housework: couples in cross-national perspective. J Marriage Fam 64, 743-755.

12. Brewster KL \& Padavic I (2004) Change in gender-ideology, 1977-1996: the contributions of intracohort change and population turnover. J Marriage Fam 62, 477-487.

13. Davis SN \& Greenstein TN (2009) Gender ideology: components, predictors, and consequences. Annu Rev Sociol 35, 87-105.

14. Fan PL \& Marini MM (2000) Influences on gender-role attitudes during the transition to adulthood. Soc Sci Res $\mathbf{2 9}$, $258-283$

15. Kroska A \& Elman C (2009) Change in attitudes about employed mothers: exposure, interests, and gender ideology discrepancies. Soc Sci Res 38, 366-382.

16. Jacobs JA \& Gerson K (2009) The Time Divide: Work, Family, and Gender Inequality. Cambridge, MA: Harvard University Press.

17. Presser HB (2003) Working in a 24/7 Economy: Challenges for American Families. New York: Russell Sage Foundation.

18. Hochschild A (1989) The Second Shift: Working Parents and the Revolution at Home. New York: Viking Penguin.

19. Corrigall EA \& Konrad AM (2007) Gender role attitudes and careers: a longitudinal study. Sex Roles 56, 847-855.

20. Lopata H (1991) Gender and social roles. In Handbook of the Sociology of Gender, pp. 229-246 [JS Chafetz, editor]. New York: Kluwer Academic/Plenum Publishers.

21. Treas J \& De Ruijter E (2008) Earnings and expenditures on household services in married and cohabiting unions. J Marriage Fam 70, 796-805.

22. Devine CM, Jastran M, Jabs JA et al. (2006) 'A lot of sacrifices': work-family spillover and the food choice coping strategies of low wage employed parents. Soc Sci Med 63, 2591-2603.

23. Kucera B \& McIntosh WA (1991) Family size as a determinant of children's dietary intake: a dilution model approach. Ecol Food Nutr 26, 127-138.

24. Pyke K \& Coltrane S (1996) Entitlement, obligation, and gratitude in family work. J Fam Issues 17, 60-82.

25. Coltrane S (2004) Research on household labor: modeling and measuring the social embeddedness of routine family work. J Marriage Fam 62, 1208-1233.

26. Sayer LC (2005) Gender, time and inequality: trends in women's and men's paid work, unpaid work and free time. Soc Forces 84, 285-303.

27. Shelton BA \& John D (1996) The division of household labor. Annu Rev Sociol 22, 299-322.

28. Kroska A (2004) Divisions of domestic work revising and expanding the theoretical explanations. J Fam Issues 25, 890-922.

29. Centers for Disease Control and Prevention (2009) NHANES 2007-2008 public data general release file documentation. http://www.cdc.gov/nchs/nhanes/nhanes2007-2008/general doc_e.htm (accessed April 2011). 
30. Centers for Disease Control and Prevention (2010) NHANES 2007-2008: Diet behavior and nutrition data documentation, codebook, and frequencies. http://www.cdc.gov/nchs/ nhanes/nhanes2007-2008/DBQ_E.htm (accessed April 2011).

31. Sanders AE (2010) A Latino advantage in oral health-related quality of life is modified by nativity status. Soc Sci Med 71, 205-211.

32. Centers for Disease Control and Prevention (2009) NHANES 2007-2008 demographic variables and sample weights data documentation, codebook, and frequencies. http:// www.cdc.gov/nchs/nhanes/nhanes2007-2008/DEMO_E.htm (accessed April 2011).

33. Hosmer D \& Lemeshow S (2000) Special topics. In Applied Logistic Regression, 2nd ed., pp. 260-351. Hoboken, NJ: John Wiley \& Sons.

34. Locher JL, Ritchie CS, Roth DL et al. (2009) Food choice among homebound older adults: motivations and perceived barriers. J Nutr Health Aging 13, 659-664.

35. Settersten RA Jr \& Ray B (2010) What's going on with young people today? The long and twisting path to adulthood. Future Child 20, 19-41.
36. Brines J (1994) Economic dependency, gender, and the division of labor at home. Am J Sociol 100, 652-688.

37. Bittman M, England P, Sayer L et al. (2003) When does gender trump money? Bargaining and time in household work. Am J Sociol 109, 186-214.

38. Gupta S (2006) Her money, her time: women's earnings and their housework hours. Soc Sci Res 35, 975-999.

39. Stevens DP, Minnotte KL, Mannon SE et al. (2006) Family work performance and satisfaction. Marriage Fam Rev 40, 47-74.

40. Brown JL \& Miller D (2002) Gender role preference and family food chores. J Nutr Educ Behav 34, 100-108.

41. Blumberg RL (1988) Income under female versus male control: hypotheses from a theory of gender stratification and data from the third world. J Fam Issues 9, 51-84.

42. McIntosh WA \& Zey M (1998) Women as gatekeepers of food consumption: a sociological critique. In Food and Gender: Identity and Power, pp. 125-144 [CM Counihan and SL Kaplan, editors]. New Delhi: Harwood Academic Publishers.

43. Becker GS (1965) A theory of the allocation of time. Econ J 75, 493-517. 